University of Nebraska - Lincoln

DigitalCommons@University of Nebraska - Lincoln

June 1975

\title{
Critical Flicker Frequency in a Harp Seal: Evidence for Duplex Retinal Organization
}

Charles D. Bernholz

University of Nebraska-Lincoln, cbernholz2@unl.edu

Michael L. Matthews

University of Guelph, Ontario, Canada

Follow this and additional works at: https://digitalcommons.unl.edu/libraryscience

Part of the Library and Information Science Commons

Bernholz, Charles D. and Matthews, Michael L., "Critical Flicker Frequency in a Harp Seal: Evidence for Duplex Retinal Organization" (1975). Faculty Publications, UNL Libraries. 95.

https://digitalcommons.unl.edu/libraryscience/95

This Article is brought to you for free and open access by the Libraries at University of Nebraska-Lincoln at DigitalCommons@University of Nebraska - Lincoln. It has been accepted for inclusion in Faculty Publications, UNL Libraries by an authorized administrator of DigitalCommons@University of Nebraska - Lincoln. 


\title{
Critical Flicker Frequency in a Harp Seal: Evidence for Duplex Retinal Organization ${ }^{1}$
}

\author{
Charles D. Bernholz and Michael L. Matthews \\ Department of Psychology, University of Guelph, Ontario, Canada
}

(Submitted March 1974; revised October 1974)

\begin{abstract}
Critical flicker frequency (CFF) was investigated in a free swimming harp seal using behavioral techniques. The resulting CFF vs intensity curve indicates a definite rod/cone break, suggesting a duplex photoreceptor population, whose presence had not been observed in previous morphological reports.
\end{abstract}

\section{INTRODUCTION}

The harp seal, Pagophilus groenlandicus (Erxleben, 1777), normally operates under a wide range of illumination conditions, ranging from murky oceanic depths of as much as $275 \mathrm{~m}$ (Nansen, 1925) to the dazzling brightness of sunlit ice (Mansfield, 1967). It might be expected that the harp seal would have a visual system capable of efficient response under these conditions manifested by duplex retinal organization, similar to other species that operate under such ambient light situations. In this case, duplicity of retinal organization may be characterized by a system with high gain and low resolution and a second complementary system of lower sensitivity but higher spatio-temporal resolution. Nevertheless, light microscopy of the retina of the harp seal (Nagy and Ronald, 1970) failed to find clear evidence of two receptor populations. Instead, receptors with cone-type pedicles were observed (Jamieson and Fisher, 1971), suggestive of Pedler's (1965) type B cell, a relatively sensitive polysynaptic receptor found in the fovea of rhesus monkeys. However, Nagy and Ronald (1970) also found a high convergence ratio of receptor to bipolar to ganglion cells $(100: 10: 1)$ that is more characteristic of a rod-populated retina. Supporting this view Lavigne and Ronald (1972) obtained behavioral data indicating that the visual system of the harp seal was capable of response under dim conditions with a terminal threshold value of $6.7 \times$ $10^{-5} \mu \mathrm{W} / \mathrm{m}^{2}$ at peak spectral sensitivity $(525 \mathrm{~nm})$. In addition, an 8-log-unit gain in sensitivity was found during the course of dark adaptation. However, they also found a 25$\mathrm{nm}$ Purkinje shift, which might be interpreted as giving indication of two receptor populations, or at least the presence of two photopigments. The latter view was adopted by Nagy (1971) who concluded, through his electron microscopy study, based on outer segment structures, that the retina of the harp seal is populated by a single class of photoreceptors containing at least two photopigments.

Clearly, in the present case, morphological description may be at variance with behavioral data, a situation that has frequently arisen in the description of the retina of animals whose receptor populations do not fit into classical receptor categories. In such instances behavioral data obtained under controlled viewing conditions is likely to provide the clue to understanding functional organization of the retina.
While many measures are available, critical flicker frequency (CFF) has been widely used in such contexts. In humans and other species with duplex retinae, it has been shown that when CFF is plotted as a function of stimulating light intensity, two branches of the curve are obtained (Porter, 1902; Piper, 1911; Granit and Riddell, 1934; Granit, 1935). There have been many demonstrations that CFF rates are not only generally higher for cones than for rods (Horsten and Winkleman, 1962; Dodt, 1967; Tigges, Brooks and Klee, 1967; Ordy and Samorajski, 1968), but that the unique contributions of the different receptor populations are evidenced by a distinct break in the CFF-intensity curve. Such findings have been obtained with the cat (Dodt and Enroth, 1954) and other species with morphologically distinct retinae, such as the sunfish, Lepomis (Crozier, Wolf and Zerrahn-Wolf, 1936); the frog, Rana pipiens (Crozier and Wolf, 1939); and the newt, Triturus (Crozier and Wolf, 1940). Evidence from species with single photoreceptor systems supports the view that CFF serves as a reliable indicator of temporal functioning of receptor systems. Species with pure cone systems tend to exhibit high CFF rates, such as the American red squirrel, Tamiasciurus hudsonicus loquax (Tansley, Copenhauer and Gunkel, 1961) or the tree shrew, Tupaia glis (Tigges et al. 1967; Ordy and Samorajski, 1968) which show rates of 65 and 90 flashes per second (fps) respectively. In addition, no transition or break is found in the CFF-intensity function for single receptor retinae as in the case of the pure cone iguana, Iguana iguana, or the pure rod Tokay gecko, Gekko gekko (Meneghini and Hamasaki, 1967). CFF rates in animals with rod only retinae show relatively low rates such as the value of $20 \mathrm{fps}$ obtained with Gekko gekko. Although there appears to be general agreement between histological evidence and flicker data, a number of discrepancies between anatomical and functional descriptions has been reported. Thus, Crozier and Wolf (1944), in a behavioral study, observed a duplex CFF contour in the soft-shelled turtle, Trionyx emori, which according to Gillett (1923) possesses an all cone retina. Again, the Phelsuma geckos were originally thought to have pure cone retinae (Tansley, 1961; Arden and Tansley, 1962), but Arden and Tansley (1962) reported breaks in the electroretinographic-CFF curves of the Phelsuma inunglis. In addition, Hamasaki (1967) presented evidence showing that the owl monkey, Aotes tvivirgatus, which was previously thought

${ }^{1}$ This research was supported by a National Research Council of Canada Grant to the second author. 
to have a pure rod retina (Jones, 1965), is found to generate a CFF curve with a definite break. In such cases it appears that the histological criteria have been inadequate to define the true retinal organization.

In view of the apparent uncertainty concerning the likely retinal composition and organization of the retina of the harp seal, we have investigated the temporal response characteristics of the visual system of the harp seal utilizing $\mathrm{CFF}$ and behavioral techniques.

\section{METHOD}

Subject

The subject was a 4-yr-old immature female harp seal, Pagophilus groenlandicus. She had served in previous visual experiments using the same operant techniques. The animal was housed alone in a 6000-gal tank of continuously flowing wellwater $\left(10^{\circ} \mathrm{C}\right)$; automatic timers maintained a $12: 12 \mathrm{hr}$ light:dark period.

\section{Apparatus}

The optical apparatus consisted of a General Radio xenon flashtube strobe whose condensed beam was focused on an aperature. A third lens collimated the beam, transmitting it through neutral density filters and an electronic shutter of $2.5 \mathrm{~cm}$ dia. The beam passed through a clear acrylic window and approximately $15 \mathrm{~cm}$ of water before striking the right eye of the selfpositioned seal. The shutter duration was $500 \mathrm{msec}$. Neutral density filters attenuated the strobe's unfiltered luminance of $17 \mathrm{~mL}$, measured at the position of the seal's eye, by 1.0, 2.0, 3.0, 4.0, $4.5,5.0,5.5,6.0$, and $7.0 \log$ units. Flash rate was monitored using a frequency counter coupled to a photovoltaic cell. Calibration of the light souice was accomplished through a Gamma 700 photometer coupled to a fiber optics probe in a waterproof housing; this probe was lowered into the water to a position equivalent to that of the seal's eye.

\section{Procedure}

Preliminary training of the animal consisted of shaping the animal's behavior through operant techniques (Blough, 1958). It was conditioned to discriminate between a flickering stimulus of $15 \mathrm{fps}$ and a fused stimulus of $40 \mathrm{fps}^{2}$ The seal began a trial by pressing a submerged paddle with her nose; this initiated the 500 msec stimulus exposure. The seal responded to the presence of a flickering stimulus by pressing a response paddle on the left side of the tank, or to the presence of a fused stimulus by responding to the right side of the tank. Only one view of the stimulus was allowed per trial; the animal had to respond in order to view the next stimulus. Correct responses to either flickering or fused stimuli received reinforcement in the form of herring; incorrect responses resulted in the sounding of a loud solenoid. The fused presentations served as catch trials to monitor the seal's overall performance level. In general, two sessions of about 30 min each were run daily during both training and testing time periods. The animal worked at her own speed; failure to work caused the paddles to be withdrawn and the session terminated. Daily food ration was only given if both sessions were completed.

Testing sessions were preceded by dark adaptation of a least one hour and were carried out in the dark. Data collection was based upon the Up-Down Transformed Response rule of Weth

${ }^{2}$ Forty fps was chosen on the basis of pilot experiments that showed that the animal was unable to discriminate between flicker rates of $40 \mathrm{fps}$ and $60 \mathrm{fps}$, which are substantially higher than reported temporal resolution figures for animals with pure rod retinae. erill and Levitt (1965). This technique permits quick but accurate threshold estimations to be determined within a range of 50-89 per cent correct responses. In the present case a threshold value of 70.7 per cent was chosen (Wetherill and Levitt, 1965); in order to achieve this level the procedure requires that manipulation of the flicker rate of the test stimulus be dependent on the animal's responses, according to the following rules: When two successive correct responses are obtained at a particular flash rate, the rate is increased by $2 \mathrm{fps}$, while a single incorrect response causes the flicker rate to be decreased by the same amount. In general, the initial flicker rate of a testing session was based upon the performance in previous sessions at which the animal responded correctly to approx 70 per cent of the test trials. If the first response to this rate was correct, the value was incremented by $2 \mathrm{fps}$ in successive steps until an error was made; the stimulus was then decreased by $2 \mathrm{fps}$ and this was taken as the beginning of run No. 1. Each unidirectional series of moves up or down the frequency scale defined a run; ten runs were collected in each testing session. The peak and valley scores on each run, with the exception of the first incorrect response, were averaged to permit determination of the 70.7 per cent threshold. Gellerman's (1932) schedule was used to intersperse among the test trials an equal number of catch trials on which the stimulus was always fused. A total of 139 testing sessions was performed with 6-12 complete and useable sessions at each of the 10 luminances.

\section{RESULTS}

The mean 70.7 per cent threshold values of the four best sessions at each intensity were used to compute a mean for that particular luminance. Best sessions were defined in terms of highest per cent correct on catch trials. These computed threshold values are shown in Fig. 1 , plotted as a function of log luminance. Probable errors for the mean of each luminance were calculated on the basis of 0.67 standard error (Peatman, 1947; Sokal and Rohlf, 1969). These probable errors, denoting the 50 per cent confidence limits (Crozier, Wolf and Zerrahn-Wolf, 1937) are also indicated in Fig. 1.

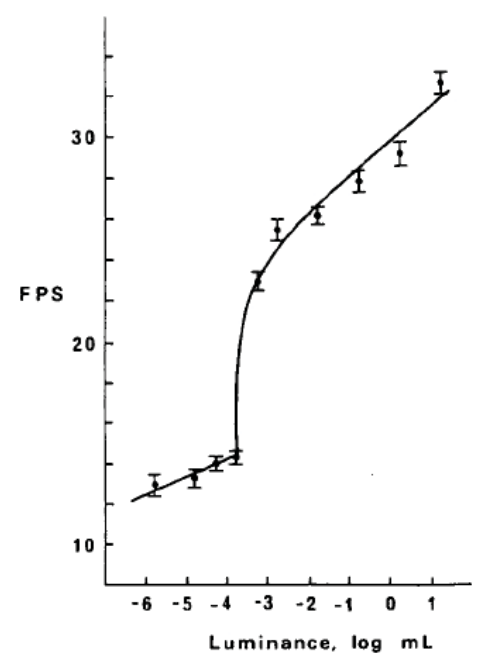

Fig. 1. Critical flicker frequency in a harp seal, Pagophilus groenlandicus. The line has been fitted by eye. Each data point is the mean of four session means. The ordinate represents the frequency in flashes per second (fps) of the $L_{0.707}$ thresholds, plotted as a function of luminance. Vertical deviations denote the probable error of each threshold. 
The function shows a clear change in slope at approx $-3.77 \log \mathrm{mL}$. In order to test whether this break was statistically significant, the data were converted to probits, based on a maximum response value of $32.7 \mathrm{fps}$ at 1.23 $\log \mathrm{mL}$. This conversion yielded two line segments whose regression line equations were $\mathrm{y}^{\wedge}=5.06+0.06 \chi$ for the lower segment, and $y^{\wedge}=6.9+0.18 \chi$ for the upper branch; r2s were 0.95 and 0.96 , respectively. A t-test on the lines suggests that the slopes are significantly different $(\mathrm{t}=$ 5.68, 3 d.f., $\mathrm{P}<0.05)$.

\section{DISCUSSION}

While the electron microscopy evidence for this seal (Nagy, 1971) clearly shows that no division can be made in classical rod/cone terms, the behavioral data suggest the existence of two functionally independent systems with differing temporal response characteristics. Similar structural versus functional disagreements have been encountered, as indicated earlier. Further evidence from a variety of species however suggests that photoreceptor classification on the basis of morphological criteria may be at times very tenuous. Pedler and Tilly (1962) and Pedler (1965) have suggested that changes in retinal components or in receptor terminals may occur without a corresponding change in the basic design of that receptor. Brown and Watanabe (1962), in their examination of the rod and cone potentials from the owl monkev, Aotes trivirgatus, suggested that functional differences may occur among receptors which show no differences in structure or contained photopigments. Hamasaki's (1967) electroretinographic-CFF work on this monkey further supports this finding. Possibly, environmental changes may cause these types of physiological adaptations. The seal, having moved to the water after extensive evolution on land (Harrison and King, 1965; Peterson, 1968), may have also experienced retinal alterations similar to those suggested for the owl monkey.

Other research with pinnipeds has not reduced the confusion in evaluating the retinal composition of these animals. While Landau and Dawson (1970) in a light microscopy study, concluded that the retinae of the Northern fur seal (Callorhinus ursinus), Northern elephant seal (Mirounga angustirostris), harbor seal (Phoca vituli$n a$ ), and California sea lion (Zalophus californianus) are "essentially cone-free", Jamieson and Fisher (1971) observed cone-like pedicles in the harbor seal, as well as in the harp seal. Furthermore, Schusterman and Balliet (1970), citing Rahmann (1967) have suggested that the visual acuity of the harbor seal, along with the Stellar sea lion (Eumetopias jubata), compares favorably with other mammals such as the elephant, antelope and cat, each of which has a duplex retina (Tansley, 1965; Dodt and Enroth, 1954; LaMotte and Brown, 1970). Additionally, Lavigne and Ronald (in press) reanalyzed the sea lion visual acuity of Schusterman and Balliet (1971) and of Schusterrnan (1972) and have shown a distinct break in the acuity contour, thereby strongly suggesting a duplex retina.

In summary, the fact that duplex visual acuity functions have been found for the California sea lion (Lavigne and
Ronald, in press) and in man (Shlaer, 1937; Hecht and Mintz, 1939); that duplex dark adaptation curves have been found in man's parafovea (Spillmann, Wolf and Nowlan, 1971), the cat (LaMotte, and Brown, 1970), and the harp seal (Lavigne, in preparation); and that duplex CFF curves have been obtained for the cat (Dodt and Enroth, 1954) and in man (Crozier et al. 1937), leads to the interpretation that the harp seal retina is probably duplex, based on the present CFF data. Since the upper limit of photopic temporal resolution as indicated by CFF appears to be mediated by receptor processes (Kelly, 1971, 1972), we further conclude that the lower segment of the CFF contour (Fig. 1) reflects rod contributions to the flicker curve and the upper branch indicates the presence of a cone or cone-like photopic receptor.

\section{REFERENCES}

Arden G. B. and Tansley K. (1962) The electroretinogram of a diurnal gecko. J. gen. Physiol. 45, 1145-61.

Blough D. (1958) A method for obtaining psychophysical thresholds from the pigeon. J. exp. Analysis Behav. 1, $31-43$.

Brown K. T. and Watanabe K. (1962) Rod receptor potential from the retina of the night monkey. Nature, Lond. 196, 547-50.

Crozier W. J. and Wolf E. (1939) The flicker response contour for the frog. J. gen. Physiol. 23, 229-38.

Crozier W. J. and Wolf E. (1940) Reaction to visual flicker in the newt Triturus. J. gen. Physiol. 23, 667-76.

Crozier W. J. and Wolf E. (1944) Theory and measurement of visual mechanisms. XII. On visual duplexity. J. gen Physiol. 27, 513-28.

Crozier W. J., Wolf E., and Zerrahn-Wolf G. (1936) On critical frequency and critical illumination for response to flickered light. J. gen. Physiol. 20, 211-28.

Crozier W. J., Wolf E., and Zerrahn-Wolf G. (1937) Intensity and critical frequency for visual flicker. J. gen. Physiol. 21, 203-21.

Dodt E. (1967) Purkinje-shift in the rod eye of the bush baby, Gulago crassicaudatus. Vision Res. 7, 509-17.

Dodt E. and Enroth C. (1954) Retinal flicker response in cat. Acta physiol. scand. 30, 375-90.

Gellerman L. W. (1932) Chance orders of alternating stimuli in visual discrimination experiments. J. genet. Psychol. 42, 206-08.

Gillett W. G. (1923) The histological structure of the eye of the soft-shelled turtle. Am. J. Ophthl. 6, 955-73.

Granit R. (1935) Two types of retinae and their electrical responses to intermittent stimuli in light and dark adaptation. J. Physiol., Lond. 85, 421-38.

Granit R. and Riddell H. A. (1934) The electrical responses of light- and dark-adapted frogs' eyes to rhythmic and continuous stimuli. J. Physiol., Lond. 81, 1-28.

Hamasaki D. I. (1967) An anatomical and electrophysiological study of the retina of the owl monkey, Aotes trivirgatus. J. comp. Neurol. 130, 163-74.

Harrison R. J. and King J. E. (1965) Marine Mammals. Hutchinson, London. 
Hecht S. and Mintz E. U. (1939) The visibility of single lines at various illuminations and the retinal basis of visual resolution. J. gen. Physiol. 22, 593-612.

Horsten G. P. M. and Winkleman J. E. (1962) Comparison of critical fusion frequency in diurnal and nocturnal retina of vertebrates. Archs int. Physiol. Biochim. 70, 660-70.

Jamieson G. S. and Fisher H. D. (1971) The retina of the harbor seal, Phoca vitulina. Can. J. Zool. 49, 19-23.

Jones A. E. (1965) The retinal structure of (Aotes trivirgatus) the owl monkey. J. comp. Neurol., 125, 19-28.

Kelly D. H. (1971) Theory of flicker and transient responses-I: Uniform fields. J. opt. Soc. Am. 61, 537-46.

Kelly D. H. (1972) Adaptation effects on spatio-temporal sine-wave thresholds. Vision Res. 12, 89-101.

LaMotte R. H. and Brown J. L. (1970) Dark adaptation and spectral sensitivity in the cat. Vision Res. 10, 703-16.

Landau D. and Dawson W. W. (1970) The histology of retinas from the Pinnipedia. Vision Res. 10, 691-702.

Lavigne D. M. and Ronald K. (1972) The harp seal, Pagophilus groenlandicus (Erxleben, 1777), XXIII. Spectral sensitivity. Can. J. Zool. 50, 1197-1206.

Lavigne D. M. and Ronald K. (In press) Evidence of duplicity in the retina of the California sea lion (Zalophus californianus). Comp. Biochem. Physiol.

Mansfield A. W. (1967) Seals of the Arctic and Eastern Can$a d a$. Fisheries Research Board of Canada, Ottawa.

Meneghini K. A. and Hamasaki D. I. (1967) The electroretinogram of the iguana and Tokay gecko. Vision Res. 7, 243-5.

Nagy A. R. (1971) A light and electronmicroscopic study of the structure of the retina of the harp seal, Pagophilus groenlandicus (Erxleben, 1777). Ph.D. thesis, Univ. of Guelph.

Nagy A. R. and Ronald K. (1970) The harp seal, Pagophilus groenlandicus. (Erxleben, 1777). VI. Structure of retina. Can. J. Zool. 48, 367-70.

Nansen F. (1925) Hunting and Adventure in the Arctic. Duffield, New York.

Ordy J. M. and Samorajski T. (1968) Visual acuity and ERG$\mathrm{CFF}$ in relation to the morphological organization of the retina among diurnal and noctural primates. Vision Res. 8, 1205-25.
Peatman J. G. (1947) Descriptive and Sampling Statistics. Harper, New York.

Pedler C. (1965) Rods and cones - a fresh approach. In Color Vision (edited by De Reuck A. V. S. and Knight J.), Ciba Foundation Symposium. Churchill, London.

Pedler C. and Tilly R. (1962) The nature of the gecko visual cell. Vision Res. 4, 499-510.

Peterson R. S. (1968) Social behavior in pinnipeds with particular reference to the northern fur seal. In The Behavior and Physiology of Pinnipeds (edited by Harrison R. J., Hubbard R. C., Peterson R. S., Rice C. E., and Schusterman R. J.), Appleton-Century-Crofts, New York.

Piper H. (1911) Uber die Netzhautstrome. Arch. Anat. Physiol. 85-132.

Porter T. C. (1902) Contributions to the study of flicker-II: Proc. R. Soc. 70A, 313-29.

Rahmann H. (1967) Cited in Schusterman and Balliet (1970).

Schusterman R. J. (1972) Visual acuity in pinnipeds. In Behaviour of Marine Animals, Vol. 2: Vertebrates (edited by Winn H. E. and Olla B. L.). Plenum, New York.

Schusterman R. J. and Balliet R. F. (1970) Visual acuity of the harbor seal and the Stellar-sea lion underwater. $\mathrm{Na}$ ture, Lond. 226, 563-64.

Schusterman R. J. and Balliet R. F. (1971) Aerial and underwater visual acuity in the California sea lion, Zalophus californianus, as a function of luminance. Ann. N.Y. Acad. Sci. 188, 37-47.

Sokal R. R. and Rohlf F. J. (1969) Biometry: The Principles and Practice of Statistics in Biological Research. Freeman, San Francisco.

Spillman L., Wolf E., and Nowlan A. T. (1971) Dark and light adaptation with opposite time courses. J. opt. Soc. Am. 61, 1122-23.

Tansley K. (1961) The retina of a diurnal gecko, Phelsuma madagascariensis longinsulae. Pflugers Arch. ges. Physiol. 272, 262-69.

Tansley K. (1965) Vision in Vertebrates. Chapman \& Hall, London. 